Military Technical College

Kobry El-Kobbah,

Cairo, Egypt

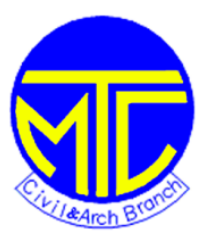

$10^{\text {th }}$ International Conference on

Civil and Architecture Engineering

ICCAE-10-2014

\title{
The challenge of camouflage in architecture as means of efficiency
}

\author{
Dr. Randa Hassan Mohamed*
}

\begin{abstract}
:
Building is one of the most dangerous activities, for both man and Earth. More dangerous when it is less useful to living, but damaging when its nature does not establish relations with the context of the place. And regarding tothe contemporary city it has lost its original meaning and its traditional shapedue to the degeneration of buildings.MeanwhileCamouflage phenomenon may be attached to the solution of such problem, as for natural species it means the concealment by means of several combined adaptations with the surrounding environment that allows the organisms to remain unnoticed to keep them living in an efficient way. And this concept has been spread within the urban context since the First World War as an intelligent deal with the space to achieve the maximum benefit with least amount of loss.

So the researcher put a hypothesis thatnowadays there are various aspects of camouflage which can be used to solve the strange problems in the urban realm but there is no real criterion appeared to design the efficient camouflage building.Although more work has been done on the so called adaptive designswhich can react reversibly to their surroundings responding to the sustainabledevelopment as; environmental, social or economical,As such designs stands for over a long period of time depending on their passive and active components, and they could be related to the concept of camouflage.

So the research aims to declare for the presence of camouflage aspects within their various shapes in architectureespecially those referring to several patterns andresponding to the efficiency issue, to give a guideline for designingefficient camouflagedbuildings.
\end{abstract}

Key words: camouflage, dazzle painting, eliminating the shape,eliminating the volume, visual detection, building visibility

\section{Introduction:}

Camouflage is properly an effective aspect which is used by man commonly in the $20^{\text {th }}$ century since the first world war because of the recent achievements in aerial warfare and ever-increasing role played by aircrafts and satellites in military operations for reconnaissance and photography, asit played more vital role in the concealment of the important objects in the urban realm[1] and its creation was largely the work of artists asthey were responsible for

*The Higher institute of Engineering, El Shorouk, Egypt, Department of architecture,

E mail:queenmerna@hotmail.com 
The vivid colors of the "dazzle painting" applied especially to the ships of the Royal Navy, as shown in fig (1).[2]

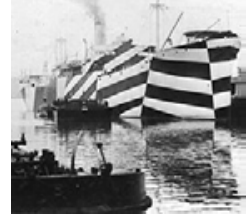

USS West Mahomet in HMS Argus displaying a coat of dazzle dazzle camouflage, 1918

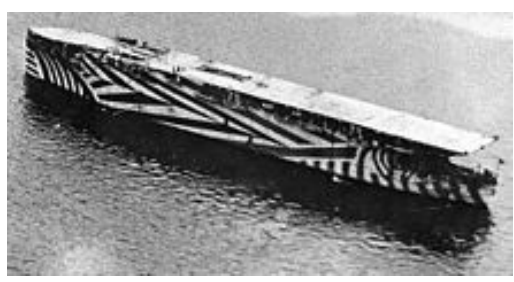
camouflage in 1918

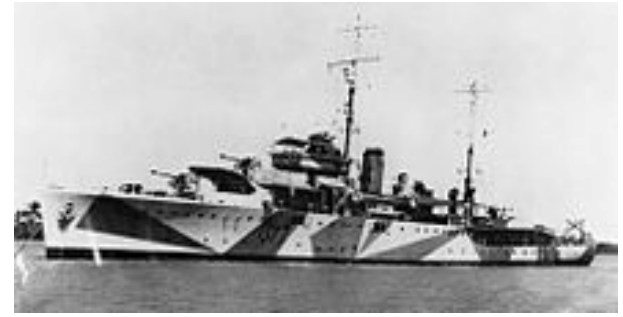

HMAS Yarra in dazzle camouflage while sailing in the Persian Gulf, August 1941

Fig (1) dazzle painting on some ships [2]

But during the Second World War, architects almost completely supplant painters in this field. And the Studies of the camouflage technique had continued uninterrupted since 1918, and camouflage departments occupied an important place in all the armed forces; In Great Britain, the Air Ministry set up a Directorate of Camouflage under the direction of Captain L. M. Glasson, in 1938. Its principal task was to prepare camouflage for the most exposed industrial targets. [3] On the other hand a number of German cities, from Berlin to Munich were taken similar measures to disguise the most characteristic urban elements: the streets, squares and monument. [4]

The use of camouflage in large cities remains to this day one of the most extraordinary chapters in the implementation of urban design strategies, especially that modernism as; social, formal idealism and architecture as it is opened to the possibility that form and content do not necessarily combined in the same container. soarchitecturecan play through mimicry whichSubvert the power of the eye and play with our perceptions at a number of levelscreating a physical and sensuous relation to the surrounding. [5]

The main attribute of camouflage aspects for eliminating the shape and volume of any organic species depends ondeceiving the eye from recognizing elements byusing theories of visual detection or assumptions of decreasing the building visibility. as these theories depend on the distance between the observer and the objects which plays an important role in the detection of these objects, as any object is visible because of the selective reflection which range in the electromagnetic wavelength between $400-750 \mathrm{~nm}$ to affect the light sensor in the human's eye, but It should be taken into consideration that as the distance between the observer and the object increases the colors and eventually differences in brightness gradually disappear. Therefore, the probability of the visual detection of the object will mainly depend on the color and the brightness contrast of the building with the background surrounding the area. [6]

The paper will promote the various applications done in architecture recently to fulfill the shapes of camouflage concerning the patterns of dazzlingand Mimicryas they fulfill the well known aspects of designing camouflage in architecture and finally criticizing them as results and discussion.

\section{Theshapes of camouflage within Dazzling;}

Dazzle camouflageis known as painting consisted of complex patterns of geometric shapes in contrasting colors, interrupting and intersecting each other, usually included a false bow wave intended to make estimation of the object's speed difficult. [7] At the same time all accepted forms of an object are broken up by masses of strongly contrasted color, consequently making it a matter of difficulty to decide on the exact course of the vessel to be attacked. The colors mostly in use were black, white, blue and green andwhen making a design for a vessel, vertical lines were largely avoided. Sloping lines, curves and stripes are by far the best and give greater distortion.[8]So it is to be said that any aspect of designing the envelope of the 
building in a way of breaking its feature into masses could be considered dazzling, and there are various aspects of design as follows:

\section{1 direct painting on the surface;}

$\underline{1}^{\text {st }}$ example; As it has been applied on the apartments of the slum dwellings in favela that was created by Dutch artists; Jeroen Koolhaas and Dre Urhahn as they hopedto develop that spaceto become lively. Then they planned to change the appearance of its apartments by dazzling its envelopes, as they called the plan as Favela Painting.and finallythe apartments became colorful representing a great and exciting art works of architectural visualization as shown in fig (2)[9]

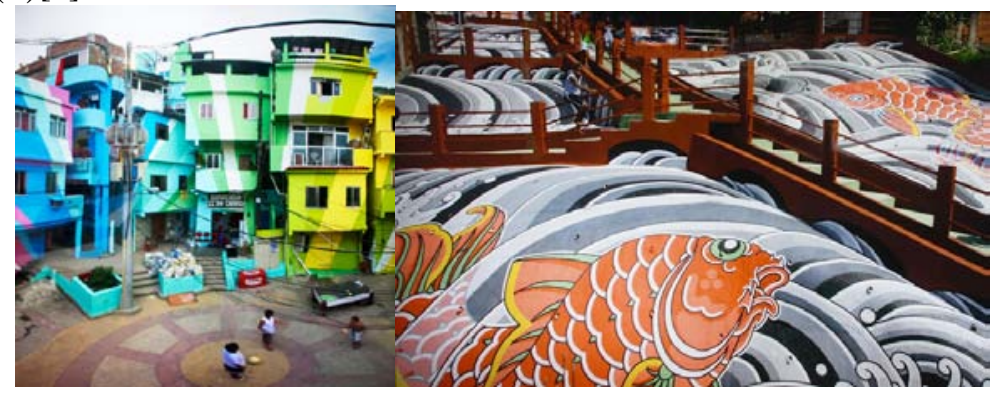

To the left the camouflage appeared as sloped colored lines on the walls of the appartements and such colors are cyan, green and yellow, while at the right the the camouflage appeared as curved lines with some fishes on the floors with use of some real wooden pathrails to convert the artificiality of the 2D painting into a virsual reality as 4D paintings.

Fig (2) The camouflage apartment of favela was created by Dutch artists, Jeroen Koolhaas[9]

$\underline{2}^{\text {nd }}$ example; Such concept was applied also in an effective way by Martin Lejarraga Architect as he designed the Municipal library and Reading Park in Torre Pacheco Spain, Fig (3) of built up area $2475 \mathrm{~m}^{2}$, as the project is a deliberate challenge to today's outlaying urban environments that seeks to hide the building under the contour.Moreover its roof is effective as a multi use item which has slopes attached to the ground floor to attract people to come over and share each other the playground painted with various games on it. [10]

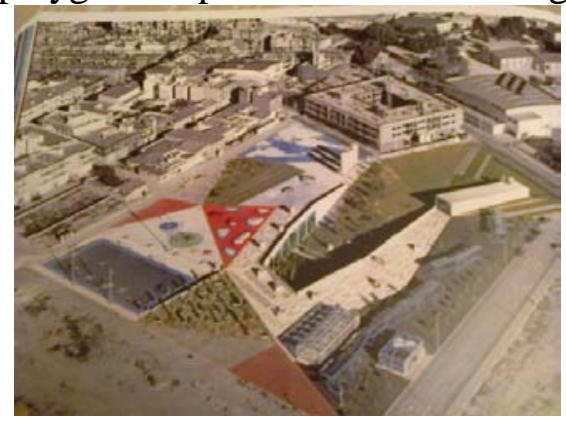

Fig (3) an aerial image of the Municipal library and reading park in Torre Pacheco Spain [10]

1.2 painting on intelligent screens; Dazzle has been appeared also in the project of the new Venice Biennale Australian pavilion fig (4) asthe designer of the project aimed torepresent Australia's nature and sculpt it into the built environment so the form of the overall building is pushed and pulled to correlate with the surrounding context, as the paintings of the envelope are presented on the louvers that will change the color as the wind blows. [11]This project achieved the camouflage principles as; color resemblance, obliterate shading, disruptive coloration. The designer applied the easiest way to conceal the building within a pattern covering the envelope and the terrain of the construction place of the new building. Moreoverthe building was erected in regions exhibiting a complex terrain pattern in the local vegetation to reduce the building detection.[12] 


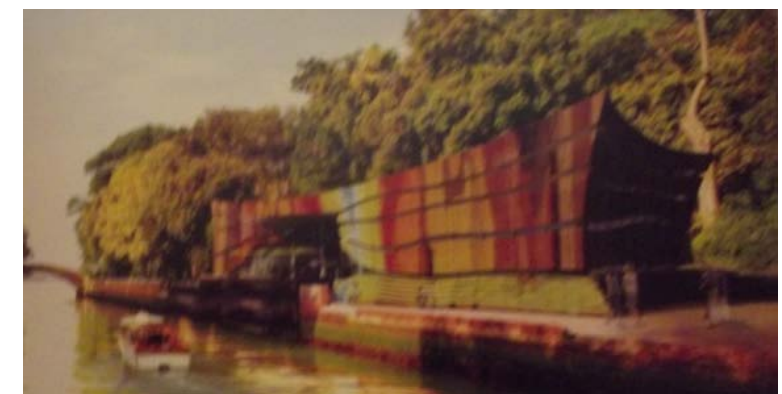

Fig (4) the new Venice Biennale Australian pavilion [11]

\subsection{Dazzling ofthe exoskeleton}

It can be divided into structural skeleton and the skin configuration one as follows;

It is an innovative and efficient way of camouflage as breaking the main features of the building by using cladding patterns that has to be organized in a way to produce required camouflage pattern, as well as producing a sustainable aspect of design. and they are as follows;

1.3.1 Loggias layer; as Challenge has made by OFIS architects specially in Slovenia to make a balance between the quality of design and the budget as the issue concerns the social housing projects as a highly regulated and defined typology with no space for innovation. the architects found the facad as an opportunity to get more square meters for the client to sell while generating better ventilations conditions and improved special qualities for the inhabitants to live in. and the project of Ljubljana 2004-2006 fig (5) for Rok Oman and partners won a competetion for developimg four apartment blocks from 125 to 140 meters in length. As the solution for the extra surface appeared to be the external pattern screen called Loggias layer which is designed far from the main facad for the plaster and the windows to add an extention for the floor area but in a uniform urban sight.[13]

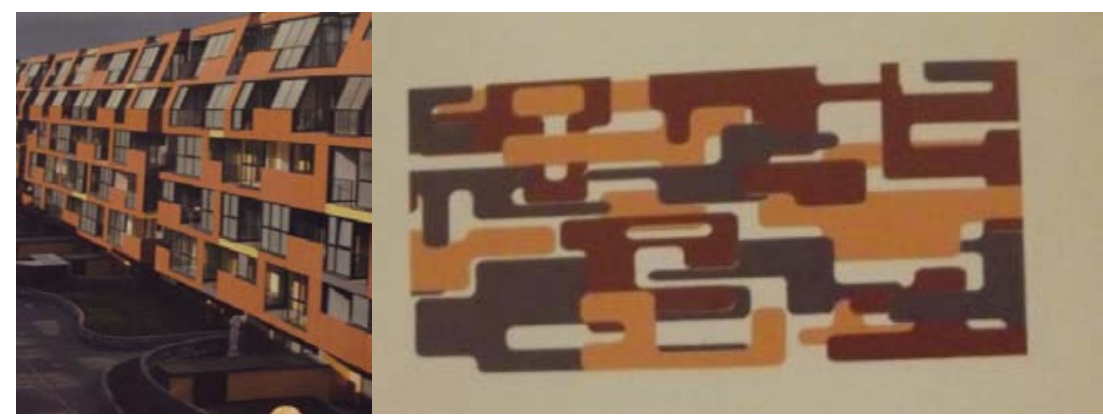

fig (5) Dazzle matches with the application of surfacing materials in Slovenia 2004-2006 for Rok Oman and partners. [13]

1.3.2 The structural diagrid exoskeleton; nowadaysmost of the global highrise buildings refer to the exoskeleton to glorify the natural lighting and the sense of the free slabs; The construction process of the o-14 towerFig (6) in Dubai, by Reiser + Umemoto, uses a concrete shell to provide an efficient structural exoskeleton, freeing core from the usual high rise structural loads and offering column free interiors. The rolled out shell illustrated here is organized as a diagrid and optimized by a system of continuously varying apertures providing the necessary structural support, whilst efficiently localizing material where it is required. This efficiency and modulation allows the shell to create a wide range of atmospheric and visual effects in the tower without altering basic structural form. Thus afford systematic analysis and construction. As a result, the towers pattern design combines a capillary branching field, gradients of vertical articulation, opacity, environmental effects and structural and turbulence field.[14] 


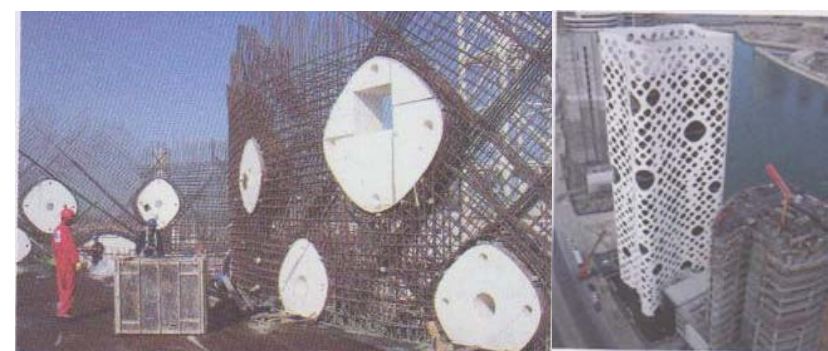

To the left the building seems to be under construction while to the right the building seems to be completed

Fig (6) the o-14 tower in Dubai, by Reiser + Umemoto[14]

1.3.3 using the static motion in the surfacing screens;Sometimes the external surfacing material responsible for camouflage may be related to static motion, as the various components of the screen could be appeared to be virtually movingto play a role of disguisingas shown in Arezzo courthouse - the Emblem of architectural art by L.Campagna and partners fig (7) which is covered externally by a multicurvelinear screen responsible for shading the envelope of the building moreover it represents a disguising means for the building. [10]

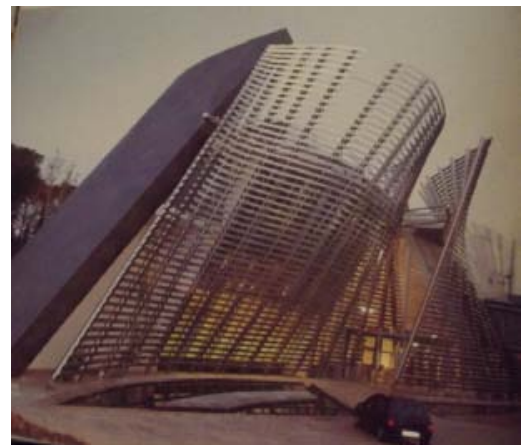

Fig (7) Arezzo courthouse - the Emblem of architectural art by L.Campagna and partners.[10]

1.3.4 using the dynamic motion in the claddings;Regarding that it can be an effective solution to break the sense of color and shape as shown in the prototype building called Passive solar habitat designed by Aaron Beyers Fig (8) which appears to be an aspect of the sustainable living and being able to co- exist with the natural environment moreover it uses the dynamic motion. As this project expands upon techniques of passive solar housing by utilizing local resources and investigating methods inspired by its natural habitat as the timber used in the claddings and all the structural elements and the design overall are perceived as a composition of recyclable materials minimizing cost, labor and site impact.Moreover it represents dazzle utilizing the movable shatter that is found externally on the envelope to protect it from hot climate and give breath to the building.[10]

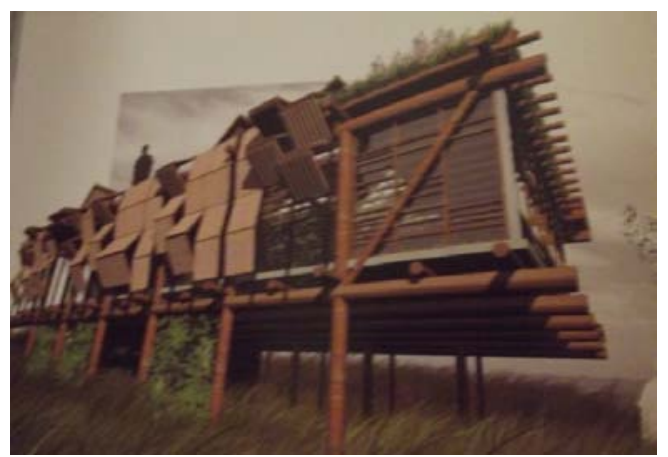

Fig (8) Passive solar habitat by Aaron Beyers [10] 


\subsection{Pixeled Digital camouflage patterns:}

The modern approaches for camouflage pattern can be distinguished into digital camouflage and active one as using the various aspects for pixel ling the image or misleading the observer, [15] [16]by using a number of small rectangular pixels of color Fig (9). In theory, it is a far more effective camouflage than standard uniform patterns because it mimics the dappled textures and rough boundaries found in nature.as this is caused by how the human eye interacts with pixilated images. The most famous particular patterns of this sort are MARPAT (USA), CADPAT (Canada) and others. Which are used in the military equipments and clothes [17]
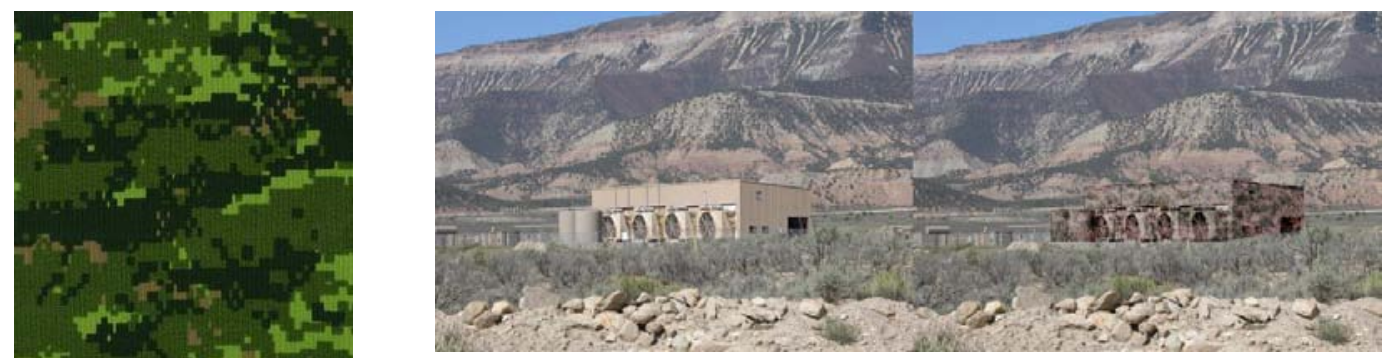

To the left Digital CADPAT camouflage pattern while to the right Building before and after application by camouflage Painting

Fig (9) Digital camouflage pattern [17]

This aspect of camouflage is shown in Krakow conference \& Concert centre, Krakow, Poland, by Yoko Sano fig (10)as the form of the building is an inherent part of the corner of the building plot at Grunwaldzkie Roundabout, the cladding of the building is a glazing one as it will be finished with glass and titanium- zinc, sheeting complemented with individually designed ceramic and stone cladding (granite, lime stone and sandstone) these elements refer the history to typical materials creating the history of architecture of the Wawel hill as it opens the perspective to the river and the old city and the Wawel castle. The combination of these various materials with the glazing creates a mosaic on the building elevations and determine its image as it diguses the main features of the openings and the typical floors it is consisting of .as well as it camouflaged also the volume of the building. [10]

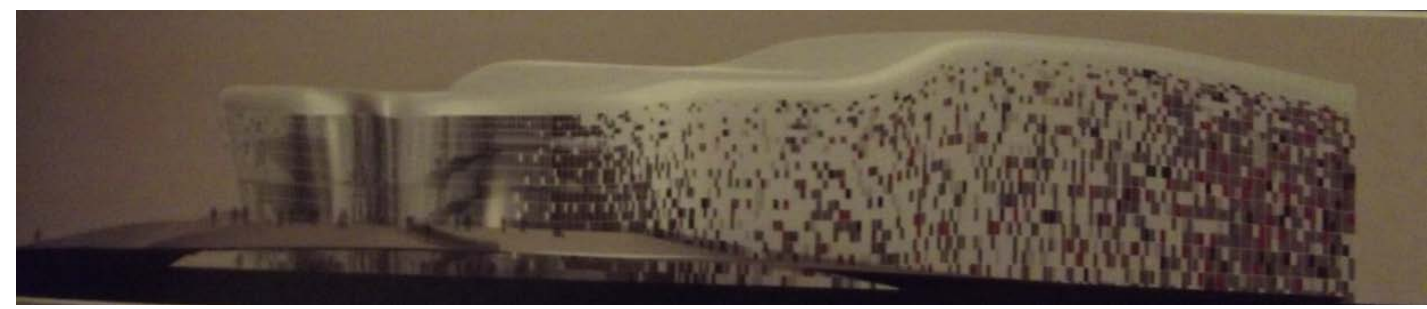

Fig ( 10) Krakow conference \& Concert centre, Krakow, Poland , by Yoko Sano ～[10]

\subsection{Using virtual formatting as breaking the volume of the building;}

as appeared in Eicher-Volvo India Headquarters building fig (11) in Gurgaon which represents a multi use building but its final shape has been disguised by forming the building as various cubes combined together and using a shading screen of aluminum louvers as wide horizontal ribs to break the mean feature of the building or disguising the number of its levels. [10] 


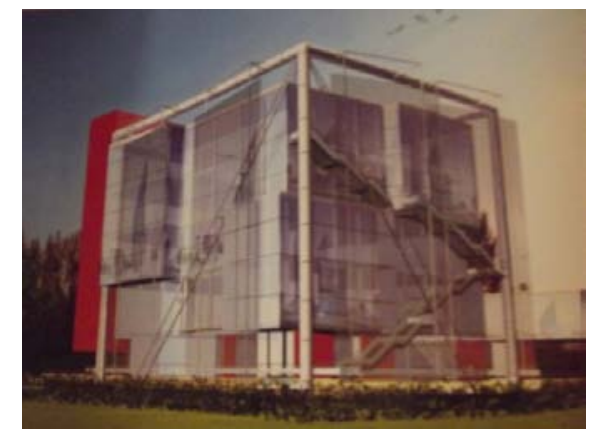

Fig (11) Eicher - Volvo India Headquarters, Gurgaon [10]

\section{The shapes of camouflage within Mimicry;}

This aspect refers to special protective resemblance where the organism looks like another object which means being seen, but resembling something else whereas crisps is being hidden, it is also called masquerade "cover-up" as the camouflaged object looks like something else which is of no special interest to the observer. [18] Mimesis is common in prey animals, for example when a peppered moth caterpillar mimics a twig, or a grasshopper mimics a dry leaf. As the resemblance is attached to elastic smart body using the elongation in motion and preferring the counter shading to hide Mimesis is also employed by some predators and parasites to lure their prey. [19], [20] and there are various shapes of mimicry appeared in architecture as follows;

2.1 photographic prints (pixilated view);Dutch designer Roeland Otten uses mosaic tiles, paint and photographic prints to disguise scruffy public buildings Fig (12) as the former public toilet in Amsterdam as the tiles provide a pixilated view of Jan van Galenstraat shopping street,Otten's project that began in 2009 with the transformation of a former electricity substation on the corner of Graaf Floristraat and Heemraadsingel in Rotterdam. And Rotterdam uses a photograph printed on aluminum as he clad the building in sheets of aluminum printed with high-resolution photographs of the surrounding streets, so that it seems almost invisible among the houses and trees. [21]
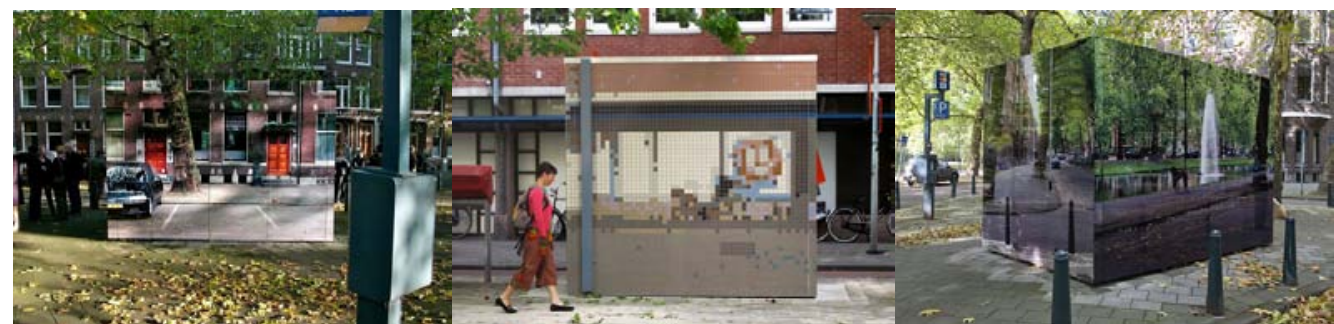

to the left appears the former public toilet in Amsterdam, in the middle Otten's project and to the right Rotterdam uses a photograph printed on aluminum

Fig (12) prints to disguise scruffy public buildings [21]

2.2 Digital patterns extrusions; Another shape for digital patterns appeared in Trutec building , Seoul ,2006 by Barkow Lei binger , fig (13) in this design a digitally controlled 2d laser cutting to form 3d polygonal façade panels ,as the aluminum window extrusions, developed from a tiled surface geometry, transform a potentially ordinary office building by employing a custom fabricated façade, because the buildings context was yet to be constructed, the façade was produced for optimal effect, forming a proactive camouflage as reflecting light, weather, people, traffic, etc, in its proximity. Through the use of CNC cutting, standard off- the shelf extrusions at angles were made, which were connected to create shallow- depth 3d crystalline glazing panels, this process results in three basic types: a $2 \mathrm{~d}$ panel, a 3d panel and a 3d panel rotated through 180 degrees. The combination of these types via a complex organizational matrix generated significant variation across the façade [14] 


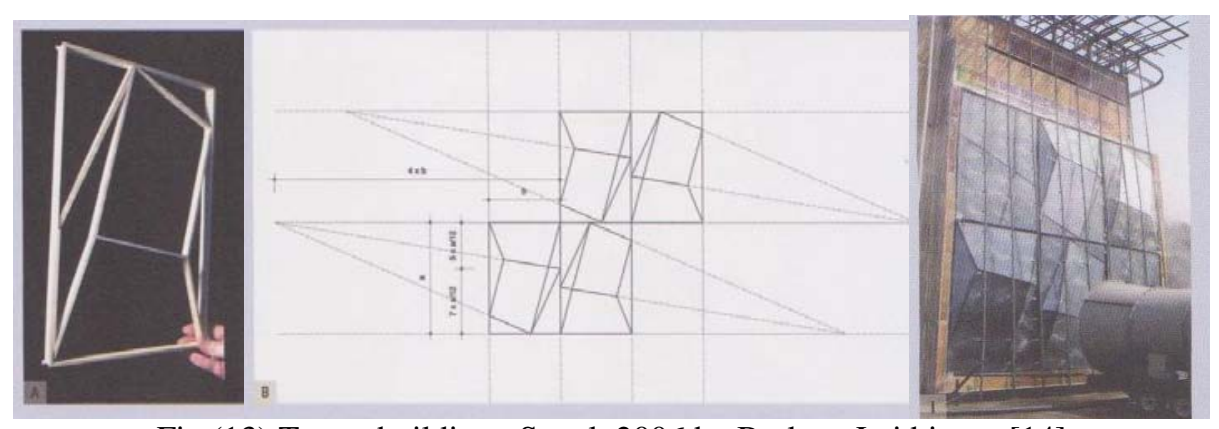

Fig (13) Trutec building , Seoul ,2006 by Barkow Lei binger [14]

\subsection{Digital media patterns;}

Another shape of patterns has been appeared by Metropolitan architectures (OMA) design for the China central television (CCTV) Headquarters proposed a digital media façade allowing the building to display moving images and footage across its envelope as shown in fig (14). [14]

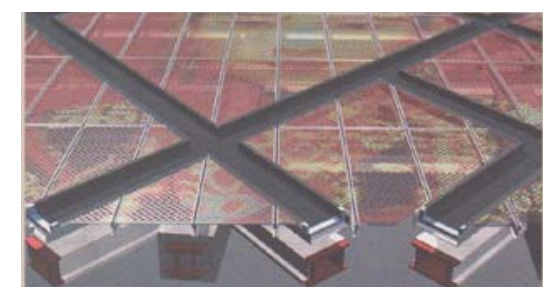

fig (14) pattern of the China central television (CCTV) envelope [14]

\subsection{Using false identical patterns;}

as The special container building in the south of Sanlitun, Hong Kong, by LOT- EK and partners as in fig (15); as a retail complex is organized like a medieval village with a dense fabric of narrow alleys, low rise buildings, elevated walkways and bridges all levels, a rhythmic system of scaffolding like metal frames is wedged between the buildings, adapting to the varying width of the alleys cross section. the scaffolding like frames are connected along the side of the building by a random system of horizontal metal rods that function as railing and braise -soleil. the rhythm of the structure is based on the width of ISO shipping containers (8 feet) which form the means of camouflage as pixel ling the main seen of the building and converts it into a seem of a collection of some ship containers accumulated one over others. [10]

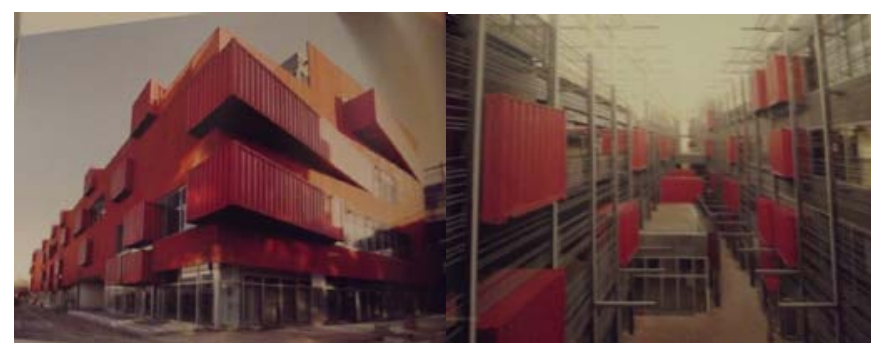

fig (15)The special container building in the south of Sanlitun, Hong Kong, by LOT- EK and partners [10]

\section{5 using cladings:}

This trend is a kind of mimicry that depends on the theory of visual detection; as The project of Antonio Vaillo I Daniel designed by Daniel Galar in Navarra fig (16) which presents a clean building that is able to coexit with other uses of a city it hids with the factories surrunding it,its outer shell layer represent a protection layer ,also it suits the green culture surrounding it. the clading is of large format sheets $(2.5 \mathrm{~m} \times 1.5 \mathrm{~m})$ are comosed of leaf - 
lacquered aluminum with , minimum thickness. The construction system of the coating is based on a process of optimization of coating material as this concept generate an image of scales swollen which reduces the volume of the building at the same time it conceal its envelope shape.[22]

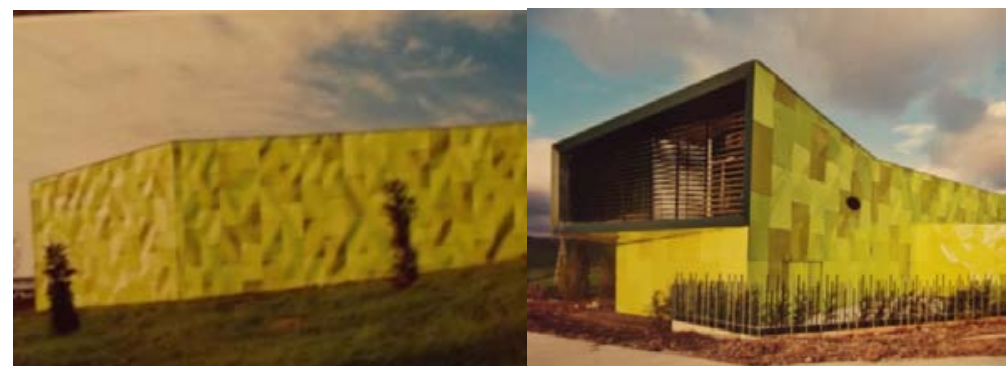

fig (16) The project of Antonio Vaillo I Daniel designed by Daniel Galar in Navarra.[22]

\subsection{The sculptural form:}

Some architects use the patterns especially in form of ribs to reduce the presence of a volume and this is found vertically or horizontally as follows:

2.6.1 The vertical pattern;as the The concept for a new mosque(La grand mousqee de Strasbourg), Strasbourg, france 2000, Fig (17)as zaha hadid in collaboration with patrik schumacher oganized a matrixwhich is established in one direction by the axis for prayer, or qibla, and the Rhine rivers curvature in the other, where the two axis intersect they fractalize and generate volume; the focus of this directional field is the mosque. The project carfully separates the buildings functions; secular spaces are at steet level, and the mosque and courtyard are lifted above ground to float above the city. A central courtyard, a contemplative space is reached from the lower, secular level and used as the entrance. Public spaces pay respect to the principles of traditional islamic architecture, with prayer rows oriented towards Mecca, water channels drifting across the ground- floor level and in the courtyard, and geometric patterns to achieve harmony and proportion. Islamic calligraphy, too is recalled in structures flowing lines.in such building the designer disguised the building with the natural topography within multicurvilinear strips as means of camouflage patters.[23]

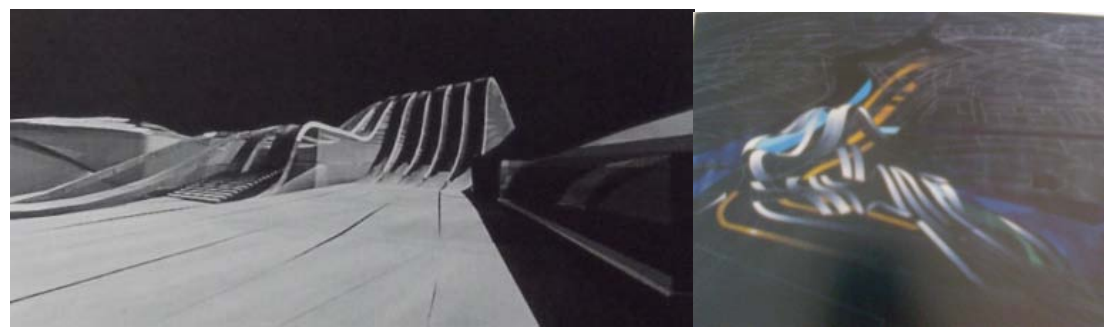

Fig (17) (La grand mousqee de Strasbourg), Strasbourg, france 2000 [23]

2.6.2 the horizontal patterns; these patterns represent a form of simple orniments on the building to convert it into Seamless pieceas shown in the Innovation tower, Hong Kong Polytechnic universety, China 2007-2011 designed by Zaha Hadid in collaboration with Patrik Schumacheras shown in fig(18); it is located at the northeast side of Hong Kong Polytechnic universety compus, will serve as a driving force in the development of the city as a design hub of Asia. Upon completion, the tower will provide some 12000 square meters of floor area and will accommodate more than 1500 students. Hong Kongs diveresity in its landscapes and history is reflected in an urbanism of layering and porosity. The architects have explorations and research into an architecture of seamless fluidity follows this paradigm, 
so evident in the city. The design dissolves the classic typology of the tower and the podium into seamless piece, and unashamedly aims to stimulate a vision of possibilities for the future, whilst reflecting the history of institution.[23]
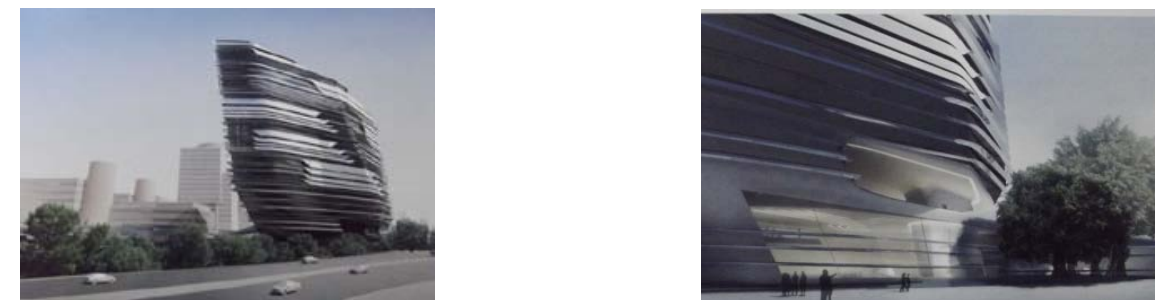

Fig (18) Innovation tower, Hong Kong Polytechnic universety, China 2007-2011, [23]

\section{Results and Discussion:}

3.1 The strategy of designing most of the globale buildings; refers to the concept of defusing the buildings and demolishing their domainance on nature. so the designers cause the inside and outside to melt together and interpenetrate, so disguising the visitor to define the space externally or internally by various tools some concerns the elimination of the shape and others refer to the elimination of the volume but most of these disguising tools play an important role in the environmental control moreover they refer to the economical aspect as the aspects of the reuse and the multifunction, moreover there is the great role inthe innovationof theconfiguration as the cycle of life always needs to create different issues completing each other to complete the cycle of creation not to stand on the old standards. So the following illustration fig (26) can refer to the main poles of the eras camouflage.

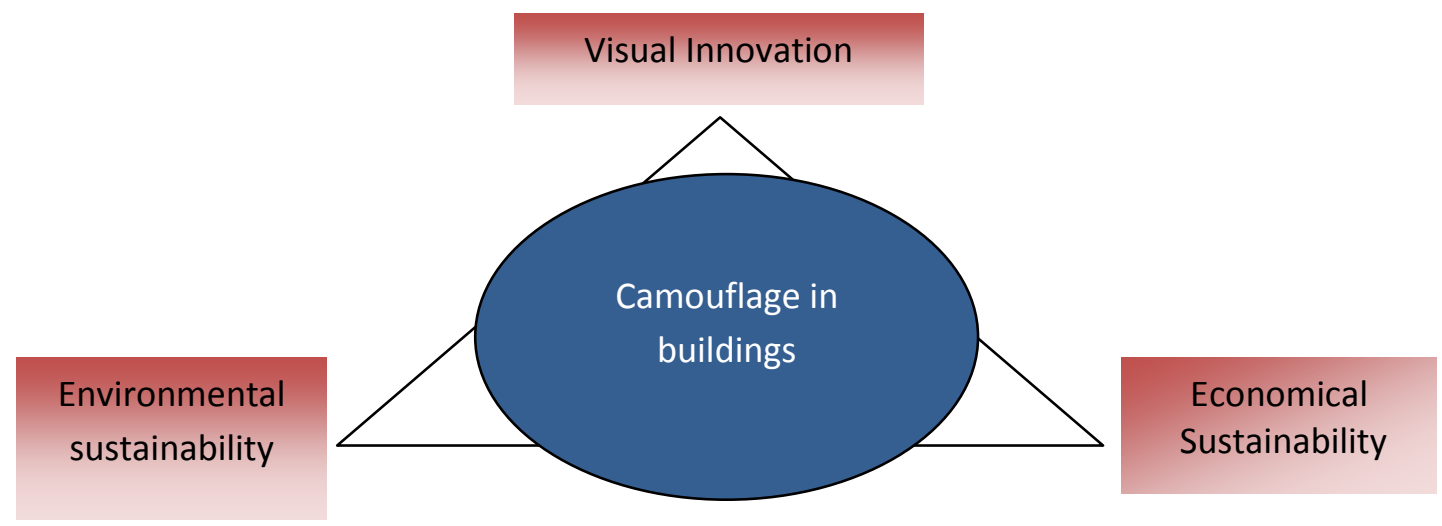

Fig (26) the three poles of camouflage in buildings

So camouflage in buildings has parameters to be aneffectiveonewhich are related to the responsibility of the visual concept, the environmental, economical and social sustainability, especially that this erais related to ecological threat which sends architecture to the frontline and the city into defensive mode. On the other hand parametric design generation is extremely useful as practitioner is able to integrate all different aspects into one large database and manipulate it accordingly.

3.2 the main concepts of camouflage in buildings; as eliminating shape and volume plays withintheories of visual detection or assumptions of decreasing building visibility as means of dazzling ormimicry (pixel ling) and both of them depend on color within pattern or using elements for configuration within patterns but with concern to the intelligence which converted the means of camouflage into a multifunctional means so the concealment trend appears to be of double face at least as visual concealment as well as the concealment from the environmental climate. 
3.3The ability to effectively communicate creative ideas;remains a central aspect of the discipline of camouflage With the development of numerous computer- aid design (CAD) and other software packages; the variety of design processes available to architects, to a stage where the imagination of the user may generate and express designs that would be difficult to achieve in traditional representational methods.

As specific interest in this field is the recent capability to integrate analogue and digital techniques and processes to produce physical objects, whether three-dimensional concept diagrams, scale models or full- size prototypes.

As the use of digital fabrication machines is typically facilitated by machines soft ware interface which may require some additional learning on behalf of the user to obtain the best results from the production processes.

As Laser - cutting machine is useful for detailed model or prototype components cut from thick paper, cardboard, acrylic sheet, thin metal sheets, slim wooden veneers or composite sheets.

So the ongoing development of digital modeling software allows design to significantly depart from the Euclidean geometrical limits that paralleled architecture thinking for many centuries, before digital technologies, curved surfaces and forms were the product of approximations using tangents to circular arcs and straight - line segments that were translated from drawings to the building sit. In freeing the designer from constrains of Cartesian space, digital modeling programs typically use the topological geometry of continuous curves and surfaces. And this will reshape the traditional urban quality; as it will be far from the traditional legibility, permeability......

So solutionof Camouflage architecture has been developed by means of technology and by the means of the needs as Camouflage started at the most basic level, at the very sources of information, with the organization of ignorance. It started with pure and simple censorship of city plans and aerial photographs to reach the most complicated phase.

3.4The relation between the pattern and camouflage; There is a complex relation between the various kinds of camouflage as each Kind is linked by one or two other kinds to be well adapted.And the various effectivepatterns rather than the painting one represent the concept of coloration which may solve many visual problems that will help in the concept of the multiuse and may assist in the role of the psychological affect on man.It will affect the form based code of any district, as this task requires materials and products with reversible properties called Property determining parameters relevant to the designed realm that can be changeable in Shape, Color (appearance), size, and function. So the camouflage will be considered as a means of hiding the building not only from its surrounding context but also from nature itself.

And we can use a simple chick list to evaluate the kind of camouflage used in buildings within patterns, as shown in table (1) below.

Table (1) the check list of qualifying the means of camouflaging the buildings

\begin{tabular}{|c|c|c|c|c|c|c|c|c|c|c|}
\hline \multirow{2}{*}{\multicolumn{2}{|c|}{$\begin{array}{l}\text { The kind of } \\
\text { concealment }\end{array}$}} & \multirow{3}{*}{$\begin{array}{r}\begin{array}{r}\text { The means of } \\
\text { concealment }\end{array} \\
\text { dazzle painting }\end{array}$} & \multirow{3}{*}{$\Delta$} & \multicolumn{7}{|c|}{ Aspects of sustainability } \\
\hline & & & & \multicolumn{3}{|c|}{ Economical } & \multicolumn{4}{|c|}{ environmental } \\
\hline 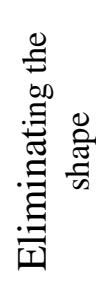 & 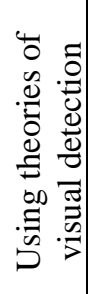 & & & 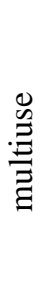 & 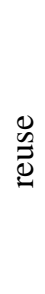 & 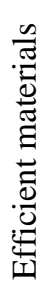 & 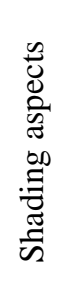 & 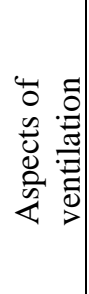 & 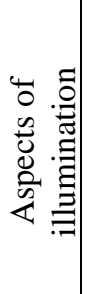 & 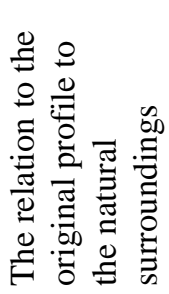 \\
\hline
\end{tabular}




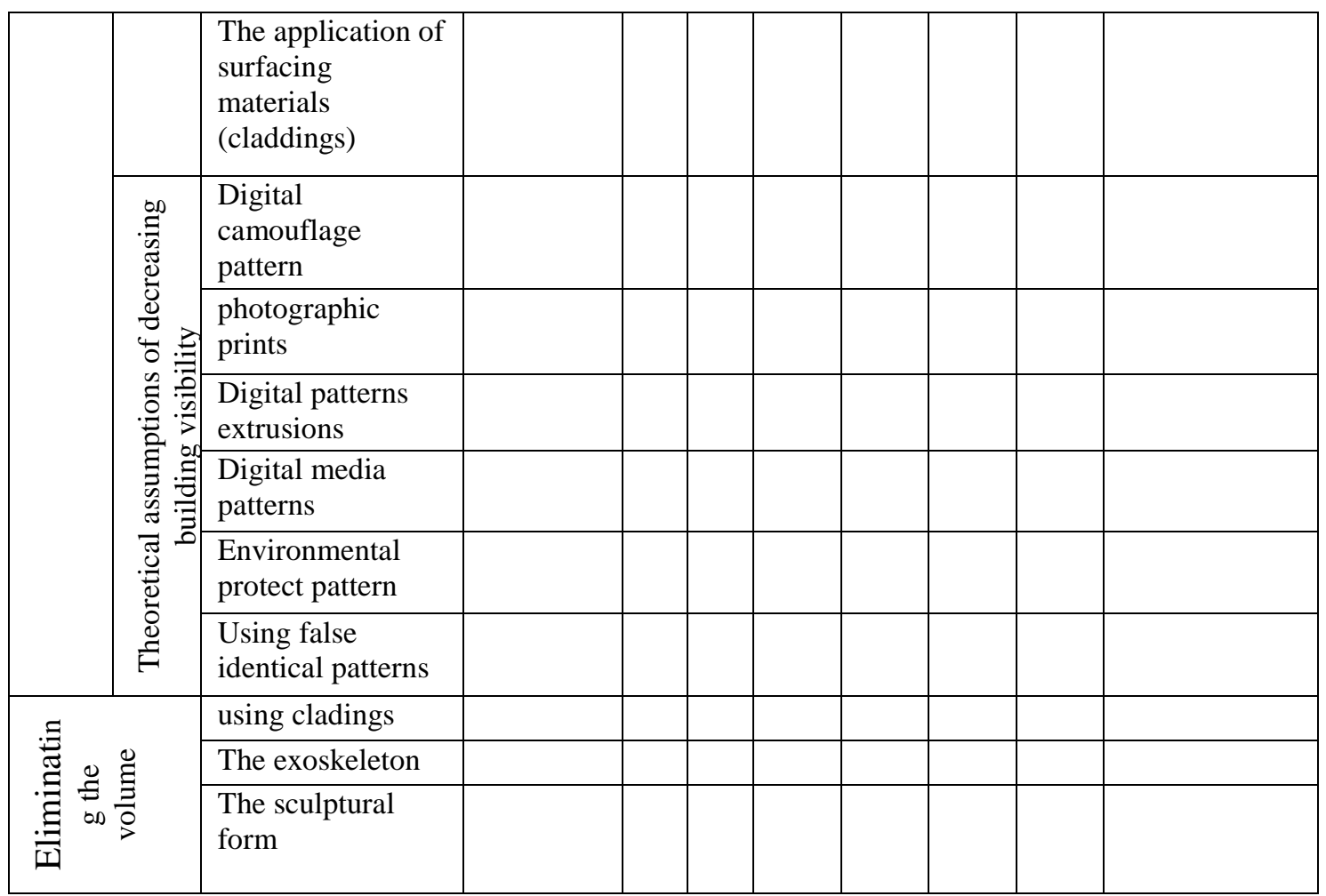

\section{Recommendations}

In fact, all camouflage solutionsneed critical strategies, as camo-theory which is the ability to employ camo is accompanied by the sensitivity and awareness to be able to distinguish others who use it. As this logic plays itself out, either camo tactics will have to keep getting better and better, or they will become self-defeating. Andevery condition is unique, because every environment is unique. And when these environments are defined broadly, any attempt at description or prescription becomes anathema to the project.

So the main precaution of using camouflage is how to conceal buildings without ignoring the main parameters for getting an adaptive building, moreover without designing a boring patterns or design.

\section{References}

[1] Behrens, R. R. "FALSE COLORS: Art, Design and Modern Camouflage". Bobo link Books,2002.

[2] Albert Roskam, “Dazzle Painting: art come camuffamento, camuffamento come art,”Casabella, no. 557 24-26,(May 1989).

[3] Guy Hartcup, 'Camouflage: A History of Concealment and Deception in War "(Newton Abbott, London and Vancouver: David and Charles) , 1979, 51ff. Henrietta Gooden, 2007,Camouflage and Art: Design for Deception in World War 2 (London: Unicorn Press), 22-23.

[4] Davide Deriu, “Between Veiling and Unveiling: Modern Camouflage and the City as a Theater of War,” in Endangered Cities: Military Power and Urban Societies in the Era of the World Wars, ed. Marcus Funck and Roger Chickering (Boston: Brill Academic Publishers), 2004,p15-34.

[5] “L’aménagement du port de Marseille,”L'Architecture d'aujourd'hui, vol. 11, no. 3-4 (1940), 16-17.

[6] Travnikova, N. P. "Effectiveness of Visual Search. Moscow": Mashinostroyenye. 1985.

[7] Murphy, Hugh and Martin Bellamy. "The Dazzling Zoologist: John Graham Kerr and the Early Development of Ship Camouflage".The Northern Mariner XIX ,April 2009

http://www.cnrs-scrn.org/northern_mariner/vol19/tnm_19_171-192.pdf

[8] Behrens, R. R. CAMOUPEDIA: A Compendium of Research on Art. "Architecture and Camouflage". Bobolink Books,2009.

[9] http://www.designboom.com/art/favela-painting-by-haas-hahn/

[10]"Architectural, Ecology+ sustainable + city future" 2010, www.hustpass.com

[11] Jiangsu peoples, A+ C "Architecture + concepts" Tianjin branch of Jiangsu peoples publishing house, Shanghai , 2011,http://www.ifengspace.cn/static/help.html 
[12] (Baumbach and Lubbe 2008; Birkemark 2008). Baumbach, J.; Lubbe, M. Using Satellite Imagery to Evaluate Land-based Camouflage Assets[viewed on May 25,2008]. Available on the Internet:<http://researchspace.csir.co.za/dspace/bitstream/10204/1 566/1/Baumbach1_2006.pdf>.

[13]OFIS architekti/ Slovenia,"OFIS_open archive files" 98-11 , D D design document serie_34, DAMDI puulishing co, Korea,2011;http://www.ofis-a.si

[14]Nick Dunn, "Digital fabrication in architecture", Laurence king Publishing, 2012.

[15]Gavrilov, V. A. 1966. "Visibility in Atmosphere. Leningrad: Gitrometeoizdat. Military Vehicle Camouflage" [viewed on May 23, 2008]. Available on the Internet: <http://www.olivedrab. com/od_mvg_camo.php3>. Newark, T. 2007. Camouflage.

[16]Jontz, S. "Marines Hope New Camouflage Uniforms Will Stand Out (While Blending in, That Is)". Magazine Stars and Strips, 10 February 2001.

[17]Cramer, G.; O’Neill T. R. "The Science of Digital Camouflage Design", October 22, 2009, Available on the Internet: http://www.hyperstealth.com/digitaldesign/ index.htm

[18] Gullan, PJ; Cranston, PS ,4th edition, (2010); The Insects. John Wiley, Blackwell. pp. 512-513. ISBN978-14443-3036-6.

[19] Beyer, Kenneth M (1999); Q-Ships versus U-Boats: America's Secret Project. Naval Institute Press. ISBN155750-044-4.

[20] McMullen, Chris (2001); "Royal Navy 'Q' Ships". Great War Primary Documents Archive. http://www.gwpda.org/naval/rnqships.htm. Retrieved 6 March 2012.

[21] http://www.dezeen.com/.../city-camouflage-by-roeland-otten/

[22]Think architect, "Global designs in architecture" ; http://www.hustpas.com,2012

[23]Thames \& Hudson, "The complete Zaha Hadid",Thames \& Hudson Ltd, London,2009. 